\title{
Study on Effects of Low Frequency Vibration on Efficiency of Die Sinking Electrical Discharge Machining
}

\author{
Huu - Phan Nguyen ${ }^{1, *}$, Ngoc - Vu Ngo ${ }^{2}$ \\ ${ }^{1}$ Faculty of Mechanical Engineering, Hanoi University of Industry, No. 298, Cau Dien Street, Bac Tu Liem District, Hanoi, Vietnam \\ ${ }^{2}$ Thai Nguyen University of Technology, Thainguyen, Vietnam
}

Received August 22, 2019; Revised September 17, 2019; Accepted September 24, 2019

Copyright $(2019$ by authors, all rights reserved. Authors agree that this article remains permanently open access under the terms of the Creative Commons Attribution License 4.0 International License

\begin{abstract}
The vibration integrated into die-sinking electrical discharge machining is a relatively new solution, so it has been creating the interest of researchers. In this paper, the authors studied the effect of low frequency vibration attached onto workpiece to efficiency of diesinking electrical discharge machining. Copper electrode and SKD61 die steel were selected to investigate. Material removal rate, tool wear rate and surface roughness were quality indicators investigated in this study. Experimental results showed that the low frequency vibration has a positive effect on the efficiency of die-sinking electrical discharge machining. Comparing to die- sinking electrical discharge machining traditional, when the vibration unit is integrated onto work-piece in die-sinking electrical discharge machining, the largest increase of material removal rate was $34.94 \%$, the greatest reduction of tool wear rate was $16.0 \%$ and the largest reduction of surface roughness was $26.36 \%$ and profile of machined surface was better.
\end{abstract}

Keywords Frequency, Vibration, Material Removal Rate, Tool Wear Rate, Surface Roughness

\section{Introduction}

Die-sinking electrical discharge machining (DSEDM) is a method which is high efficiency in shaping complex cavity surfaces in mold, tooling, aerospace and atomic industries. The research results have been introduced in prestigious international journals and it provides a number of methods to improve the efficiency of DSEDM such as mixing powder into dielectric fluid, integrating vibration into machining process and clarify also the working principle of DSEDM. The vibration integrated into the machining process is still a relatively new solution, so it has been creating the interest of researchers.

Pandey and Singh [1] showed that vibration can be attached to electrode or work- piece. Compared to vibration integrated into electrodes in DSEDM, vibration integrated with the work- piece in DSEDM is simple and it is easy to apply in practice. Therefore, the research results in DSEDM with vibration integrated into the work- piece will have high practical significance. The number of research results in DSEDM has very little vibration integration. Therefore, it is necessary to clarify the effect of integrated vibration on workpiece to DSEDM process.

The results of vibration studies integrated into workpiece in DSEDM have shown the effect of vibration in DSEDM. Zhu et al. [2] studied vibration with low frequency $(F=150-300 \mathrm{~Hz})$ that was attached on electrode in DSEDM to process W9Mo2 $\mathrm{Cr} 4 \mathrm{~V}$ material. This study showed that material removal rate (MRR) was increased while tool wear rate (TWR), surface roughness (SR) and white layer thickness were reduced. Unune and Mali [3] used low frequency vibrations attached on Inox718 work- piece in DSEDM and research results showed that MRR increased $27.6 \%$ when the frequency of vibrations increased $(\mathrm{F}=0-40 \mathrm{~Hz})$, electrode wear rate increased $6.16 \%$, over cut and taper angle deviation decreased $31.84 \%$ and $18.58 \%$, respectively. Mwangi et al. [4] investigated the effectiveness of low- frequency vibration attached on electrodes in DSEDM with dielectric fluid and oil and water. The results showed that MRR increased, TWR decreased with both cases studied, and water solvent gave higher efficiency than oil. Kumar and Grover [5] have shown that integrating vibrations in $\mu-$ EDM is relatively difficult to apply because the micron electrode is very susceptible to vibration and deviation. Todkar et al. [6] used low frequency vibrations attached on Ti-6Al-4V work-piece in DSEDM. This study showed that 
efficiency of this method increased approximation of $40 \%$ and short- circuit pulses were approximation of $80 \%$. Prihandana et al. [7] also investigated low-frequency vibration in the work- piece in DSEDM for RB-SiC. Several results of integrated vibration research in DSEDM were introduced by Maity and Choubey [8]. And studies are mainly surveys with small cavities. On the other hand, the results of the studies will be dependent on size of workpiece and electrode, materials, technological parameters and vibration characteristics. Therefore, research to clarify the impact of vibration on productivity and quality in DSEDM is necessary to study.

In this study, the authors investigated the effect of low frequency vibration on machining efficiency in DSEDM. Copper and SKD61 die steel is used as a studied object. Efficiency of machining process will be assessed through quality indicators such as MRR, SR, TWR and profile of machined surface.

\section{Experimental System}

\subsection{Experimental Setup and Machine Details}

In this study, SKD61 steel has been used as work- piece specimen that the size is $25 \times 25 \times 30 \mathrm{~mm}$ in length, width and height, respectively. This material is importance for fabricating hot forging, casting and injection molds. The electrode which is copper has been chosen with the diameter size of $25 \mathrm{~mm}$. The fluid dielectric of machine process was D323 oil.

The experimental investigations were conducted on Chemer DSEDM machine (CM 323C). The work- piece was attached to the vibration protection fixture for the vibration unit to facilitate stable and accurate transmission of vibrations, as shown in Fig. 1 and Fig. 2. The vibration unit (Model: Exciter 4824, Brüel \& Kjær, Denmark) was used to investigate the influence of vibrations in DSEDM process. The maximum force generated by the vibrating head was $100 \mathrm{~N}$ and the maximum displacement between two peaks was $24.5 \mathrm{~mm}$ when the vibration was set to the lowest frequency vibration. The frequency vibration range of $2-5000 \mathrm{~Hz}$ produces oscillations which are sine, pulse and random signals. The amplitude of the vibrations for a chosen frequency value has been selected as $0.75 \mu \mathrm{m}$. The process parameters, as shown in Table 1, such as current (I), pulse on time $\left(\mathrm{T}_{\mathrm{on}}\right)$, pulse off time $\left(\mathrm{T}_{\mathrm{of}}\right)$, frequency of vibration $(\mathrm{F})$ have been selected as input factors for investigation.

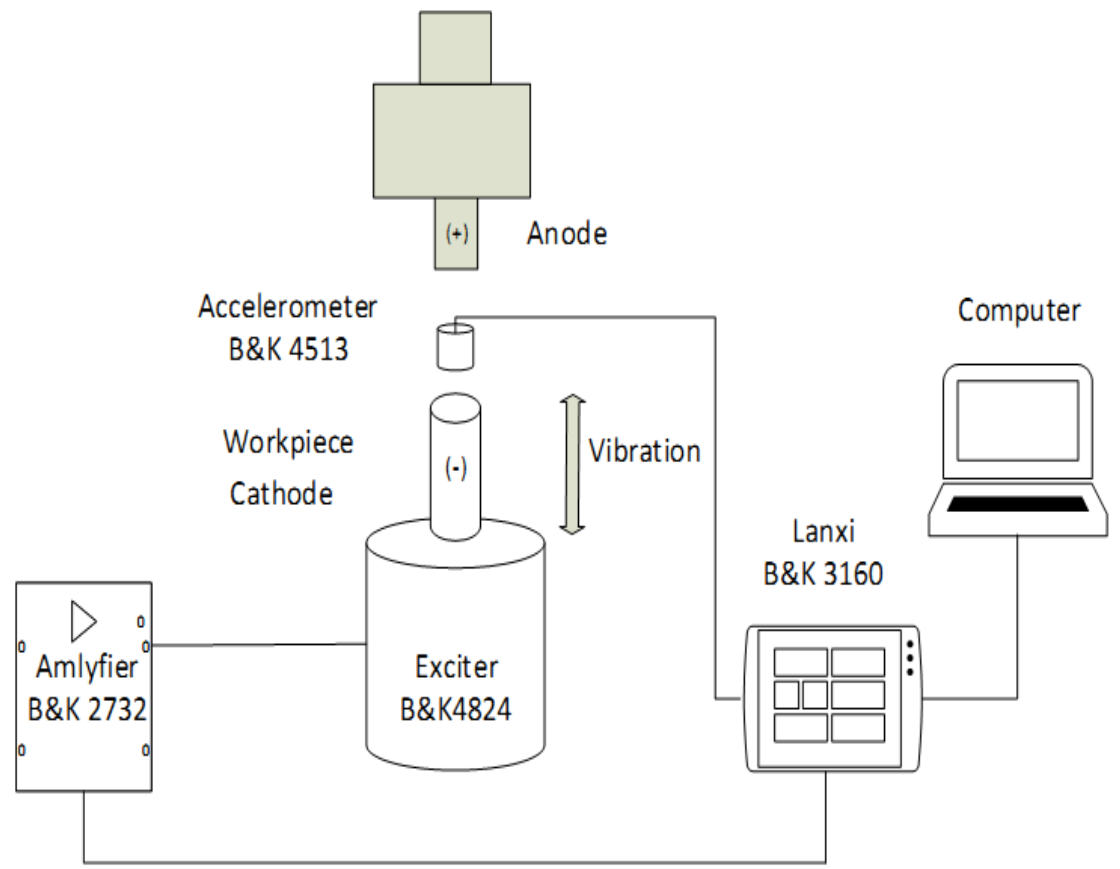

Figure 1. The experimental chart depicting the vibration setup and data logger 


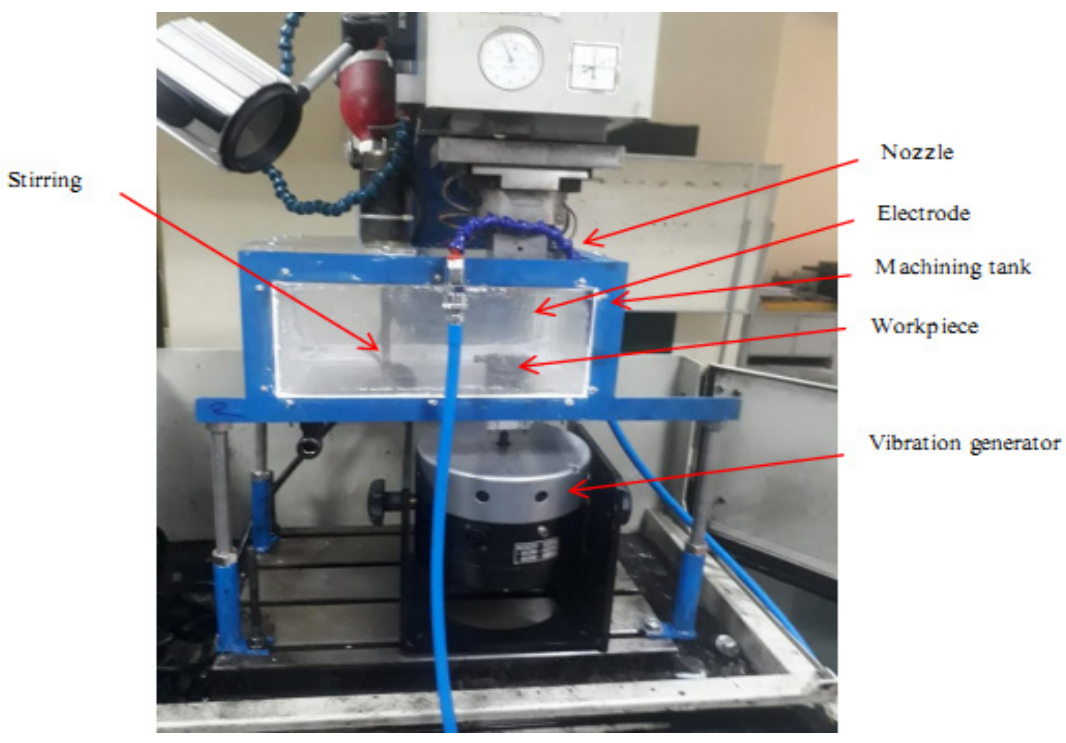

Figure 2. Experimental system

Table 1. Experimental results of MRR, SR and TWR.

\begin{tabular}{|c|c|c|c|c|c|c|c|c|c|c|}
\hline $\begin{array}{c}\text { Exp. } \\
\text { No }\end{array}$ & $\begin{array}{c}\mathrm{I} \\
\text { (A) }\end{array}$ & $\begin{array}{l}\mathrm{T}_{\text {on }} \\
(\mu \mathrm{s})\end{array}$ & $\begin{array}{l}\mathrm{T}_{\text {of }} \\
(\mu \mathrm{s})\end{array}$ & $\begin{array}{c}\mathrm{U} \\
(\mathrm{V})\end{array}$ & Electrode polarity & $\begin{array}{c}\mathrm{F} \\
(\mathrm{Hz})\end{array}$ & $\begin{array}{c}\mathrm{a} \\
(\mu \mathrm{m})\end{array}$ & $\begin{array}{c}\text { MRR } \\
\left(\mathrm{mm}^{3} / \mathrm{min}\right)\end{array}$ & $\begin{array}{c}\text { SR } \\
(\mu \mathrm{m})\end{array}$ & $\begin{array}{c}\text { TWR } \\
\left(\mathrm{mm}^{3} / \mathrm{min}\right)\end{array}$ \\
\hline 1 & \multirow{4}{*}{8} & \multirow{4}{*}{25} & \multirow{4}{*}{12.5} & \multirow{4}{*}{90} & \multirow{4}{*}{+} & 0 & 0 & 2.035 & 3.87 & 1.756 \\
\hline 2 & & & & & & 200 & \multirow{3}{*}{0.75} & 2.243 & 2.85 & 1.475 \\
\hline 3 & & & & & & 400 & & 2.316 & 3.43 & 1.821 \\
\hline 4 & & & & & & 600 & & 2.746 & 3.95 & 1.934 \\
\hline
\end{tabular}

\subsection{Quality Indicators}

Material removal rate (MRR) has been calculated based on the volume of material removed per time. It is a key parameter that affects the productivity and time of the machining process. The volume of the removed material was calculated based on the weight of the work- piece before and after machining. It is calculated by Equation (1), as follows:

$$
\operatorname{MRR}\left(\frac{\mathrm{mm}^{3}}{\min }\right)=\frac{\mathrm{w}_{\mathrm{b}}-\mathrm{W}_{\mathrm{a}}}{\rho_{\mathrm{W}} \cdot \mathrm{t}} \cdot 1000
$$

where $\mathrm{W}_{\mathrm{b}}$ is the weight of the work- piece before machining (gram) and $\mathrm{W}_{\mathrm{a}}$ is the weight of the work- piece after machining (gram). The variable $t$ is the processing time (minute) and $\rho_{\mathrm{w}}$ represents the density $\left(\mathrm{gram} / \mathrm{cm}^{3}\right)$ of the work-piece material.

Tool wear rate (TWR): The volume of electrode material eroded per minute has a significant effect on the machining precision and cost. The TWR was defined in the same way as the MRR. It is calculated by Equation (2). The corrosion defective electrode measurement process was similar to the erosion measurement of the work- piece.

$$
\operatorname{TWR}\left(\frac{\mathrm{mm}^{3}}{\mathrm{~min}}\right)=\frac{\mathrm{T}_{\mathrm{b}}-\mathrm{T}_{\mathrm{a}}}{\rho_{\mathrm{T}} \cdot \mathrm{t}} \cdot 1000
$$

where $T_{b}$ is the weight of the tool before machining (gram) and $T_{a}$ is the weight of the tool after machining (gram). The variable $t$ is machining time (minute) and $\rho_{\mathrm{T}}$ is the density of the tool material $\left(\mathrm{gram} / \mathrm{cm}^{3}\right)$.

Surface roughness (SR): This indicator directly affects the smoothness of the surface after machining, and this will determine the choice for the next machining solution after DSEDM.

\subsection{Experimental Equipment}

The weight of the work- piece and electrode were determined using a digital scale device (Model: Vibra AJ-203 Shinko, Japan). The specifications included a maximum weight limit of $200 \mathrm{~g}$ with an accuracy of \pm 0.001 $\mathrm{g}$ for repetitions of $10 \mathrm{mg}$.

The surface roughness was measured using a profile-meter device (Mitutoyo, Japan) which has a contact probe type (SJ-210). The evaluation length was $5 \mathrm{~mm}$. Measurements were acquired for each test sample and the average value of each measurement was considered. In addition, a scanning electron microscope (Jeol-6490 JED2300 , JEOL, Japan) was used to investigate the surface morphology.

\section{Results and Discussion}

\subsection{Effect of Frequency (F) to MRR, TWR and SR}

Effect of frequency to MRR. Experiments with the 
same machining conditions for DSEDM and DSEDM with vibration unit attached to work- pieces at frequencies of $200 \mathrm{~Hz}, 400 \mathrm{~Hz}$ and $600 \mathrm{~Hz}$ were performed. Experimental results showed that vibrations with low frequencies have a relatively significant effect on MRR. Comparing to DSEDM, MRR of DSEDM with vibration has a significant increase because the vibrations of work-piece increase the chip push effect and create better dielectric fluid circulation in the gap between the tool electrode and the work- piece. It were $10.22 \%, 13.81 \%$ and $34.94 \%$ with $\mathrm{F}=200 \mathrm{~Hz}, \mathrm{~F}=$ $400 \mathrm{~Hz}$ and $\mathrm{F}=600 \mathrm{~Hz}$, respectively. During the machining process, the size of the gap discharges increases and allows a cleaner dielectric solution to enter the machining gap more easily. When the work-piece is moved upwards, it creates a pumping effect that pushes the dielectric fluid with the contaminants and chip particles away from the gap. When the work-piece is attached the vibration unit, the energy of the discharge process is higher due to the vibration frequency of the electrode and the work- piece is similar in the gap discharging, and it generates more discharge times. At frequency of $300 \mathrm{~Hz}$, $400 \mathrm{~Hz}$ and $600 \mathrm{~Hz}$ with $0.75 \mu \mathrm{m}$ fixed amplitude, MRR is the largest at $600 \mathrm{~Hz}$ and stronger at $\mathrm{F}=400-600 \mathrm{~Hz}$ and it is bigger than one at $\mathrm{F}=0-400 \mathrm{~Hz}$, as shown in Figure 3 . With the same amplitude, the vibration frequency at $\mathrm{F}=$ $300 \mathrm{~Hz}$ produces a lower penetration rate of dielectric fluid than one is at $\mathrm{F}=400 \mathrm{~Hz}$, resulting in lower MRR. The highest MRR is achieved at $600 \mathrm{~Hz}$. The vibration assigned to the workpiece will affect the process of pushing the chip and absorbing the dielectric fluid at the discharge gap [8]. The downward- moving workpiece creates a new pump of dielectric fluid into the machining zone, this leads to a more stable process. During the down movement of the workpiece, the amount of sparking gap increases and allows the entrance of clean dielectric fluid. When the workpiece moves straight up, it pumps the contaminated dielectric fluid, and it increases the pressure to push the chip out of the discharge gap. Discharge energy is more intense as the tool electrode and the workpiece are brought closer more frequently. Low frequency vibrations associated with the workpiece produce the shortest

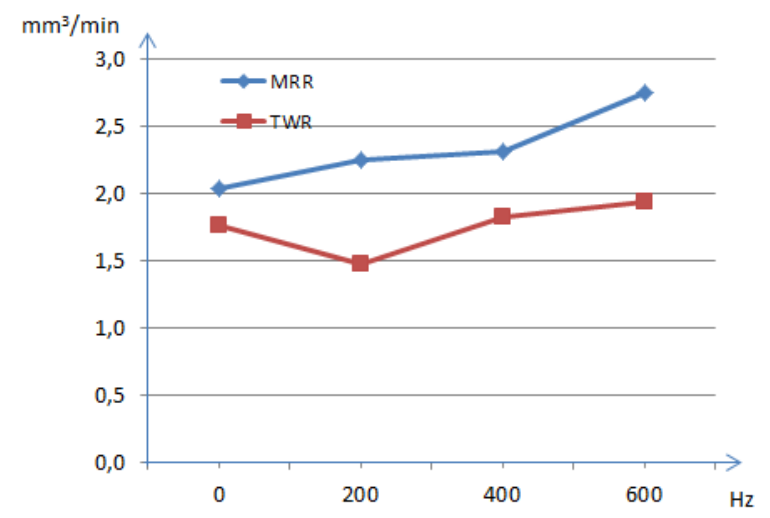

a) MRR, TWR distance more often, compared to the case of the workpiece without vibrations. This leads to an increase in the number of discharges of the spark.

Effect of frequency to SR. The obtained results are the average values of 3 iterations at $F$ frequencies of $200 \mathrm{~Hz}$, $400 \mathrm{~Hz}$ and $600 \mathrm{~Hz}$. Experimental results have shown that, with different values of frequency, roughening of the work- piece may increase or decrease comparing to the surface roughness after DSEDM. Surface roughness were $26.36 \%$ and $11.37 \%$ at $\mathrm{F}=200 \mathrm{~Hz}$ and $\mathrm{F}=400 \mathrm{~Hz}$, respectively. This may be explained that vibration unit on the work-piece makes the chip be pushed out of the gap to discharge more easily, and this will reduce the number of particles adhering to the machining surface, therefore, surface roughness is better. However, the surface roughness increased $2.63 \%$ at $\mathrm{F}=600 \mathrm{~Hz}$ and with $\mathrm{F}=$ $400-600 \mathrm{~Hz}$, productivity increased and the number and depth of the carters on machined surface will also increase. From the experimental result, it can be concluded that low frequency vibration contributes to a better surface roughness. The pressure of the electric fluid flow increases, it results in the debris being pushed out of the gap between the electrode and the workpiece being increased accordingly. This will result in a reduced number of particles adhering to the workpiece surface. In addition, the energy of each spark is reduced, and it leads to the size of the crater is reduced. That is the reason for SR reduction.

Effect of frequency to TWR. Efficiency of vibration to tool wear rate was also investigated, as shown in Fig.3. Experimental results showed that comparing with $\mathrm{F}=0 \mathrm{~Hz}$, TWR was decreased approximation of $16.0 \%$ at $F=200 \mathrm{~Hz}$. However, at $\mathrm{F}=400 \mathrm{~Hz}$ and $600 \mathrm{~Hz}$, TWR and MRR increase gradually which are $3.7 \%$ and $10.1 \%$, respectively. However, increase of MRR is bigger than one of TWR when frequency increases. This can be explained that during the machining of holes, although the machining process does not proceed further, the material is continuously removed from the tool electrode, resulting in extensive electrode wear leaving the drilling incomplete. This shows that vibration has a positive impact on machining efficiency.

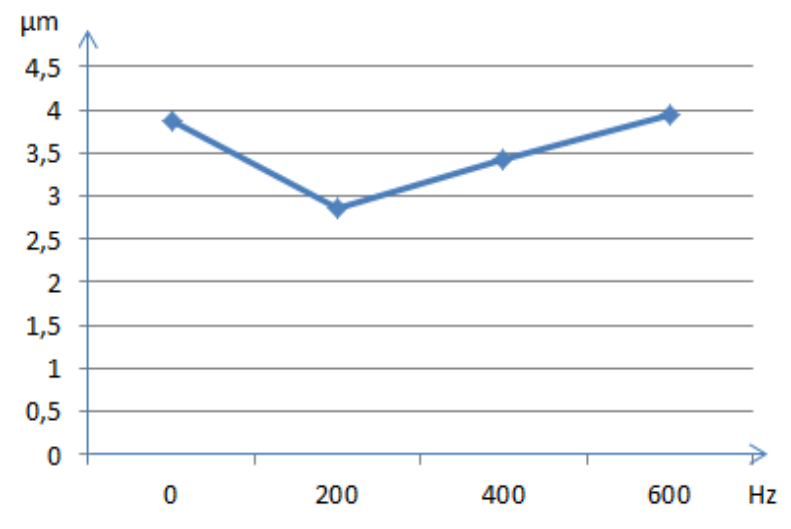

b) SR

Figure 3. Relationship chart of frequency (F) with MRR, SR and TWR 


\subsection{Effect of Frequency on Machined Surface Profile}

Profile of machined surface was changed by vibration integrated into machining process, as shown in Fig. 4. Results indicated that number of leak on machined surface roughness using die-sink DSEDM integrated into work-piece increased significantly. This problem derives from number of discharge times between electrode and work-piece increased [9]. Sizes of leak on machined surface roughness are similar lightly. The height of the rough peaks on the machining surface in DSEDM with vibration is quite uniform. After conventional and vibrational DSEDM, the machined surface is a collection of many craters of different sizes that are randomly distributed. This is due to the energy of the sparks produced during the pulse cycles that melted and evaporated at the workpiece material. Each spark created a crater on the machining surface, and the mass of the metal separated from each crater is proportional to the volume and depth of the dent. This can contribute to increase working ability of machined surface. SR is the smallest with $F=200 \mathrm{~Hz}$, however $\mathrm{F}$ is increased, it can lead to the instability of the discharge process, and this will lead to an increase in the SR.

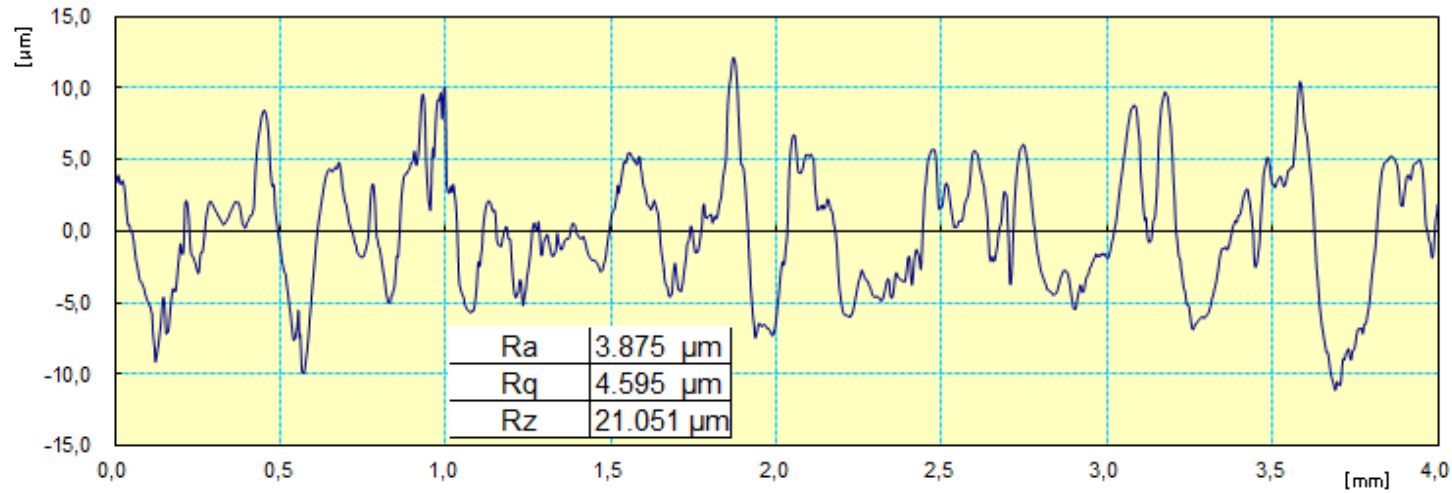

a. $\mathrm{F}=0 \mathrm{~Hz}$

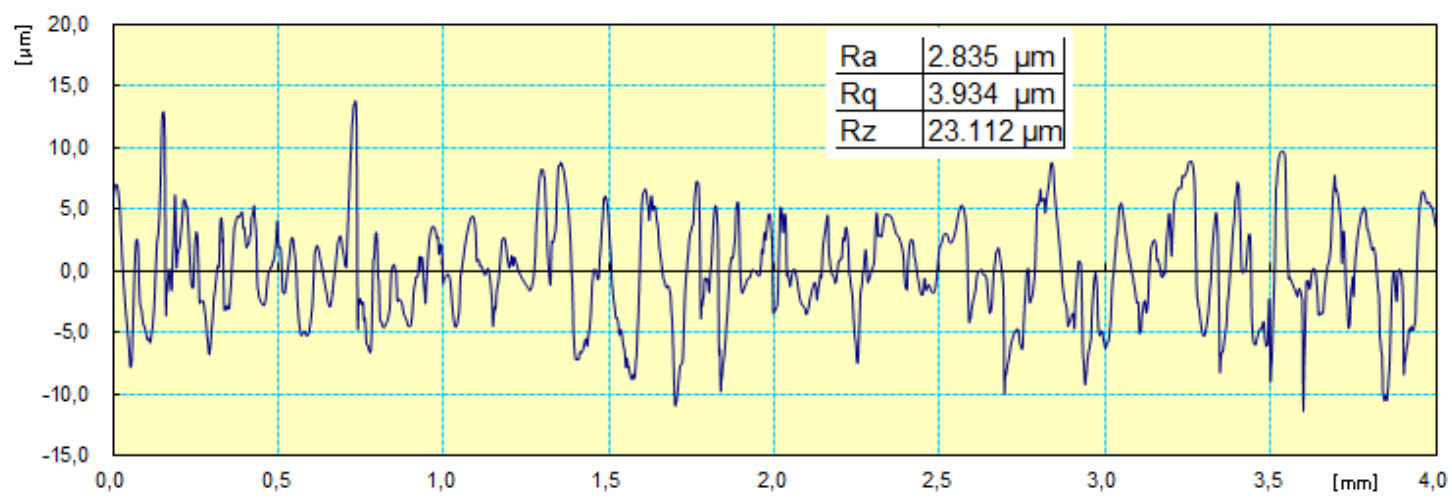

b. $\mathrm{F}=200 \mathrm{~Hz}$

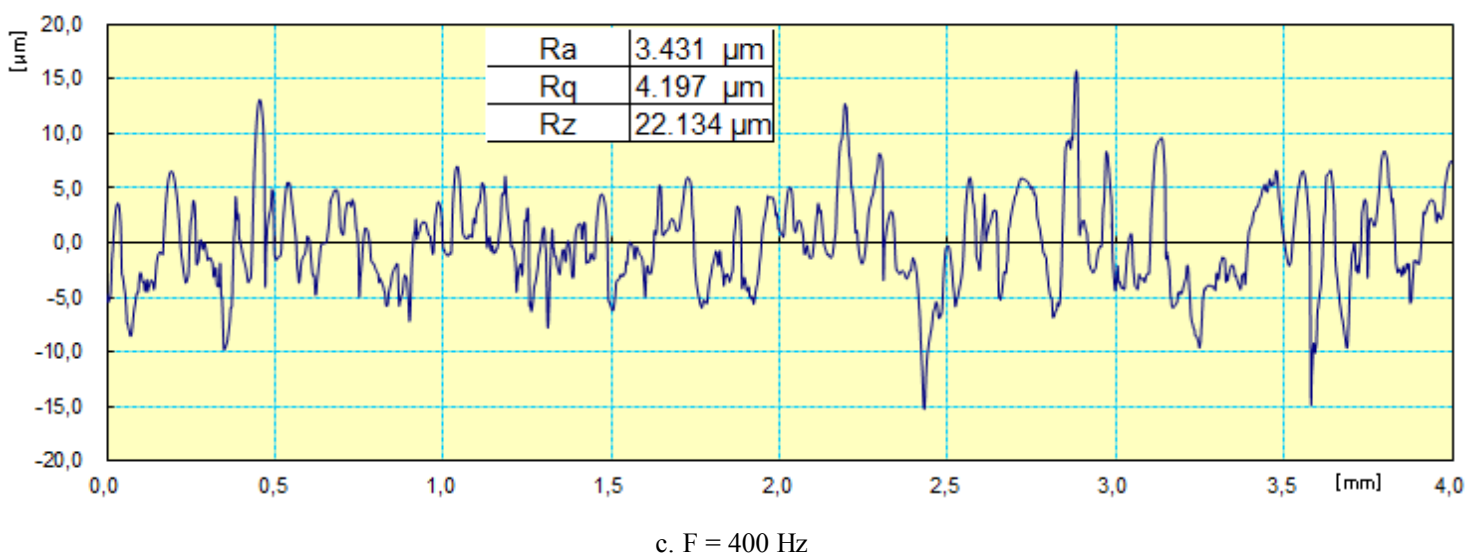




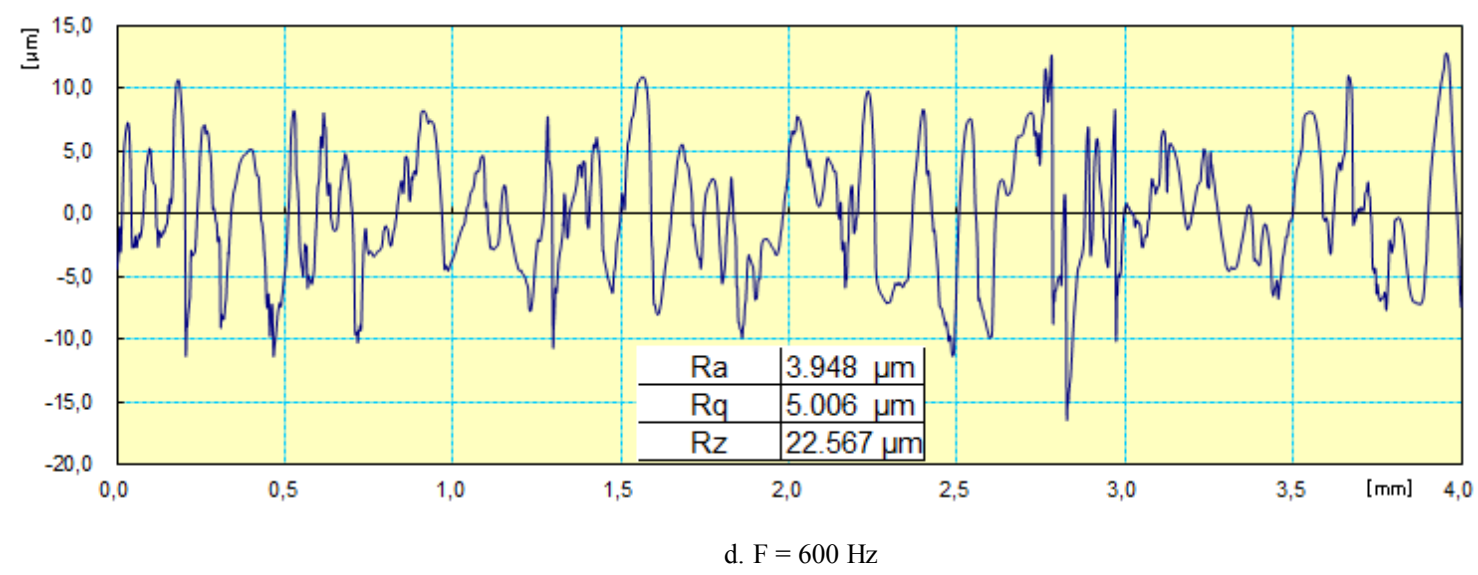

Figure 4. Profile of machined surface

\section{Conclusions}

Study efficiency of low frequency vibration attached onto the workpiece to productivity of machining process for SKD61 using DSEDM shows that:

- MRR increased significantly when frequency vibration increased. The largest increase of MRR was $34.94 \%$ at $\mathrm{F}=600 \mathrm{~Hz}$ because the vibration of workpiece in DSEDM has significantly improved the ability to remove the chip from the discharge gap and the number of spark discharges in the pulse duration has been significantly increased.

- TWR also decreased when vibration unit was integrated into the work-piece. The largest reduction of TWR was $16.0 \%$ at $\mathrm{F}=200 \mathrm{~Hz}$.

- Comparing to EDM, machined surface quality in DSEDM with low frequency vibration is also significantly improved in favor of the next finishing process. The maximum reduction of SR was $26.36 \%$ and the profile of the machined surface was more uniform.

- The efficiency of machining process in DSEDM has significantly improved with low frequency vibration attached onto the work- piece. However, further researches are necessary to clarify the machining mechanism, optimizing technological parameters and integrating vibration in powder mixed DSEDM. These contribute to confirm the effectiveness of this technology solution in practice. pp.1073-1080 (2018).

[3] Unune, D.R., Mali, H.S.: Experimental Investigations on Low Frequency Workpiece Vibration in Micro Electro Discharge Drilling of Inconel 718. Proceedings of 6th international \& 27th all india manufacturing technology, design and research conference 2016, pp.1413-1417 (2016).

[4] Mwangi, J., Ikua, B.W., Nyakoe, G.N., Zeidler, H., Kabini, S. K.: Effect of Low Frequency Vibration in Electrical Discharge Machining of AlSiC Metal Matrix Composite. Journal of Sustainable Research in Engineering 1(2) pp.45-50, (2014).

[5] Kumar, S., Grover, S.: Optimisation.strategies in ultrasonic vibration assisted electrical discharge machining: a review. Int. J. Precision Technology 7(1), pp.51-83 (2017).

[6] Todkar, A.S., Sohani, M.S., Kamble, G.S., Nikam, R.B.: Effects of Vibration on Electro Discharge Machining Processes. International Journal of Engineering and Innovative Technology 3(1), pp.270-275 (2013).

[7] Prihandana, G. S., Sriani, T., Mahardika, M.: Improvement of machining time in micro-EDM with workpiece vibration and graphite powder mixed in dielectric fluid, Indian Journal of Engineering \& Materials Sciences 19, 375-378 (2012).

[8] Maity, K.P., Choubey, M.: A review on vibration-assisted EDM, micro-EDM and WEDM. Surface Review and Letters 26(5) (2018).

[9] Phan, N.H., Duc, N.V., Bong, P.V.: Application of response surface methodology for evaluating material removal in rate die-sinking EDM roughing using copper electrode, Science \& Technology Development Journal - Engineering \& Technology 1(1), pp.20-27 (2018).

\section{REFERENCES}

[1] Pandey, A., Singh, S.: Current research trends in variants of Electrical Discharge Machining: A review. International Journal of Engineering Science \& Technology, 2(6), pp.2172-2191 (2010).

[2] Zhu, G., Zhang, M., Zhang, Q., Song, Z.C., Wang, K.: Machining behaviors of vibration-assisted electrical arc machining of $\mathrm{W}_{9} \mathrm{Mo}_{3} \mathrm{Cr}_{4} \mathrm{~V}$. Int J Adv Manuf Technol. 96(1-4), 